\section{Anthracene Oxidation in an Aqueous Sodium Hypochlorite Solution}

\section{Abstract}

Anthracene was used as a model compound for condensed aromatics in coals and liquid fuels. Its oxidation in aqueous sodium hypochlorite solution at $30^{\circ} \mathrm{C}, 40^{\circ} \mathrm{C}$ and $50^{\circ} \mathrm{C}$ was investigated, respectively. The results from gas chromatography/ mass spectrometry analysis show that anthracene can be converted to 22 products completely within $48 \mathrm{~h}$. Non-chloro-substituted compounds are the main products and their total yield is much higher than that of chloro-substituted compounds, especially in the reaction for $96 \mathrm{~h}$. Anthraquinone is the most abundant product and its yield reached maximum in the oxidation for $96 \mathrm{~h}$ at $40^{\circ} \mathrm{C}$. The mechanisms for anthracene oxidation and chlorination are discussed.

Keywords: Anthracene; Aqueous sodium hypochlorite solution; Superoxide anion radical; Oxidation; chlorination

Received: July 29, 2015; Accepted: December 17, 2015; Published: December 24, 2015

\section{Introduction}

Coals are much richer in condensed aromatic rings (CARs) than other fossil resources [1]. Many processes for converting coals to energy, such as gasification and combustion, involve oxidation. In addition, coal oxidation under mild conditions is considered to be a promising process to obtain valuable chemicals [2,3]. Therefore, understanding the mechanisms for the oxidation of CARs in coals is of great importance. On the other hand, condensed aromatics in liquid fuels are considered to be one of the major sources producing undesired exhaust emissions and causing hazardous and carcinogenic effects [4]. Converting the condensed aromatics to saturated components usually needs high hydrogen pressure and expensive catalysts. Alternative technology for removing condensed aromatics from liquid fuels should be taken into account. Sodium hypochlorite ( $\mathrm{NaOCl}$ ) is an effective oxidant for converting CARs in coals to benzenepolyoxylic acids along with small amounts of their chloro-substituted analogs and other species [5]. However, it is not clear how the CARs are oxidized in aqueous sodium hypochlorite solution. In this study, we used anthracene as a model compound for condensed aromatics in coals and liquid fuels and investigated its oxidation in aqueous sodium hypochlorite solution under mild conditions to understand how the condensed aromatics are oxidized and how to control the oxidation.

\section{Experimental}

Anthracene, $\mathrm{CH}_{3} \mathrm{CN}, 37 \%$ hydrochloric acid, diazomethane, $\left(\mathrm{CH}_{3} \mathrm{CH}_{2}\right)_{2} \mathrm{O}$, aqueous sodium hypochlorite solution (6\% available

\section{Li-Man Qie, Xian-Yong Wei, Jin-Na Li, Qing Wei, Zhi-Min Zong, Jie Lv, Hai-Yun Lu, Xing-Zhen Qi, Gui-Zhen Gong, Zi-Shuo Yao, Fang-Jing Liu, Xing Fan and Wei Zhao}

\begin{abstract}
Key Laboratory of Coal Processing and Efficient Utilization, Ministry of Education, China University of Mining and Technology, Xuzhou 221116, Jiangsu, China
\end{abstract}

\section{Corresponding author: Xian-Yong Wei}

wei_xianyong@163.com

Key Laboratory of Coal Processing and Efficient Utilization, Ministry of Education, China University of Mining and Technology, Xuzhou 221116, Jiangsu, China.

Tel: +8651683885951

Citation: Qie B, Wei X, Li J, et al. Anthracene Oxidation in an Aqueous Sodium Hypochlorite Solution. J Org Inorg Chem. 2015, 1:1.

chlorine), and anhydrous $\mathrm{Na}_{2} \mathrm{SO}_{3}$ are commercially purchased analytical reagents. Anthracene was purified by recrystallization in methanol followed by vacuum desiccation at $50^{\circ} \mathrm{C}$ for $2 \mathrm{~h}$. Other organic reagents were distilled before use. Anthracene $(0.5$ $\mathrm{mmol})$, aqueous sodium hypochlorite solution $(20 \mathrm{~mL}), \mathrm{CH}_{3} \mathrm{CN}$ $(5 \mathrm{~mL})$, and a magnetic stirrer were added into a glass tube reactor (inner volume $50 \mathrm{~mL}$ ) in a J-KEM Synthesizer. The reactor was heated to a described temperature $\left(30^{\circ} \mathrm{C}, 40^{\circ} \mathrm{C}\right.$ or $\left.50^{\circ} \mathrm{C}\right)$ and the mixture in the reactor was stirred at the temperature for a described period of time. After separating the unreacted anthracene from the reaction mixture, $1 \mathrm{~g}$ anhydrous $\mathrm{Na}_{2} \mathrm{SO}_{3}$ was added into the reaction mixture to destroy excess $\mathrm{NaOCl}$ followed by acidification with a proper amount of $37 \%$ hydrochloric acid to $\mathrm{pH} 2-3$. Then the treated reaction mixture was repeatedly extracted with $\left(\mathrm{CH}_{3} \mathrm{CH}_{2}\right)_{2} \mathrm{O}$ to afford extract solution. Concentrated extract solution was obtained by removing most of $\left(\mathrm{CH}_{3} \mathrm{CH}_{2}\right)_{2} \mathrm{O}$ from the above extract solution with a Büchi R-210 rotary evaporator, esterified with diazomethane in $\left(\mathrm{CH}_{3} \mathrm{CH}_{2}\right)_{2} \mathrm{O}$ and 
analyzed with a Hewlett-Packard 6890/5973 gas chromatograph/ mass spectrometer (GC/MS). The GC is equipped with a capillary column coated with HP-5 (cross-link 5\% PH ME siloxane, $30 \mathrm{~m}$ length, $0.25 \mathrm{~mm}$ inner diameter, $0.25 \mu \mathrm{m}$ film thickness). The MS is operated in electron impact (70 eV) mode and a quadrupole analyzer is used as a mass analyzer.

\section{Results and Discussion}

Anthracene were completely converted within $72 \mathrm{~h}, 48 \mathrm{~h}$ and 48 $\mathrm{h}$ when the reaction temperature was set to $30^{\circ} \mathrm{C}, 40^{\circ} \mathrm{C}$ and $50^{\circ} \mathrm{C}$ respectively. As Figures 1-3 exhibit, 22 compounds were identified with GC/MS. The compounds can be classified into non-chlorosubstituted compounds (NCSCs, i.e., peaks 4-6, 10-12, and 15) and chloro-substituted compounds (CSCs, i.e., peaks 1-3, 7-9, 13, 14, and 16-22), as shown in Table 1 and Figure 4. The total yield of NCSCs is much higher than that of CSCs, especially in the reaction for $96 \mathrm{~h}$. Anthraquinone is the most abundant product and its yield increased first and then decreased with prolonging the reaction time. In addition, the yield of anthraquinone from anthracene oxidation at $40^{\circ} \mathrm{C}$ is much higher than these at $30^{\circ} \mathrm{C}$ and $50^{\circ} \mathrm{C}$, and reached the maximum $(74.8 \%)$ in the oxidation for $96 \mathrm{~h}$ at $40^{\circ} \mathrm{C}$. These facts indicate that selective formation of NCSCs (especially anthraquinone) can be achieved by controlling the reaction time and temperature. Interestingly, chlorine-substituted acetic acids only appear in the products from anthracene oxidation at $30^{\circ} \mathrm{C}$ and $50^{\circ} \mathrm{C}$ and chloroanthracenes were only detected in the products from anthracene oxidation at $40^{\circ} \mathrm{C}$, although the reason needs investigating. The oxidation of coals [6-10] and their related model compounds [11-13] in aqueous sodium hypochlorite solution were extensively investigated. The oxidation of wheat straw [14] and rice husk [15] in aqueous sodium hypochlorite solution was also examined. Superoxide anion radical $\mathrm{O}_{2}$. is generally considered to be an active intermediate [16-19] for oxidizing unsaturated moieties, especially for CARs. However, to our knowledge, no reports clarified the mechanisms for the formation of $\mathrm{O}_{2}^{-}$in aqueous sodium hypochlorite solution and the reaction of $\mathrm{O}_{2}$ - with CARs. Ref. [20] proposed that $\mathrm{O}_{2}$ can directly abstract hydrogen on CARs to induce the oxidation of CARs. Such abstraction is extremely difficult, because the resulting aryl radicals are quite labile. Similarly, hydrogen abstraction from CARs by $\mathrm{O}_{2}^{-}$is also impossible. As Scheme 1 illustrates, there are ionization equilibriums between $\mathrm{NaOCl}$ and its resulting $\mathrm{Na}^{+}$and ${ }^{-} \mathrm{OCl}$ and between ${ }^{-} \mathrm{OCl}$ and its resulting $\mathrm{O}_{2}{ }^{-}$and $\mathrm{Cl}_{2}{ }^{-}$. Due to much larger superdelocalizablity (1.314) at 9-position than that at other positions in anthracene [21], $\mathrm{O}_{2}$ - tends to attack 9-position in anthracene. Thereby, the addition of $\mathrm{O}_{2}^{-}$to 9-position in anthracene should be the initial and crucial step for anthracene oxidation. The subsequent step could be the elimination of $-\mathrm{OH}$ to get 9-oxy-10-anthryl radical (OAR) followed by $\mathrm{O}_{2}^{-}$addition to the 10-position in OAR and subsequent elimination of $-\mathrm{OH}$ to produce anthraquinone. The addition of $\mathrm{Cl}_{2}^{-}$to the 9-position in anthracene can also be considered, but subsequent elimination of $\mathrm{HCl}$ is impossible. Instead, $\mathrm{Cl}_{2}^{-}$tends to react with $\mathrm{Na}^{+}$to get $\mathrm{NaCl}$ and $\mathrm{Cl}$. The resulting $\mathrm{Cl}$ can attack the 9-position in anthracene, but the well known coupling reaction from $2 \mathrm{Cl}$ to produce stable $\mathrm{Cl}_{2}$ is much more competitive. Since the distance between 2 chlorine atoms in $\mathrm{Cl}_{2}$ is substantially smaller than that between 2 carbon atoms in the 9- and 10-positions in anthracene, the addition of $\mathrm{Cl}_{2}$ to the 9- and 10-positions seems to be difficult. As a result, $\mathrm{Cl}_{2}$ prefers to add to the 1- and 2-positions to induce anthracene chlorination (Scheme 1). The superdelocalizablity of either the 1-position (1.073) or 2-position (0.922) is much smaller than that of the 9-position in anthracene, leading to much lower reactivity of anthracene toward chlorination than toward oxidation in aqueous sodium hypochlorite solution. Phthalic acid (PA) is the most abundant byproduct and its yield steadily increased by prolonging the reaction time. Detection of isobenzofuran-1,3dione, 3- and 4- chlorophthalic acids (CPAs) indicates that both dehydration and chlorination of PA proceeded, as displayed in Scheme 2. The CPAs were not detected until the reaction for 120 $h$, suggesting that PA chlorination is difficult.

\section{Conclusions}

The mechanisms for anthracene oxidation and chlorination were reasonably proposed by this investigation. The addition of $\mathrm{O}_{2}^{-}$to the 9-position in anthracene plays a crucial role in the formation of anthraquinone. According to the result, some coal conversion processes, especially mild coal oxidation, may involve in $\mathrm{O}_{2}$ addition to active sites of CARs in coals. Selective coal oxidation to afford specific oxygen-containing aromatics, like anthraquinone, could be achieved by controlling the reaction conditions. Such a process not only provides a probe for understanding the structures of CARs in coals, but also facilitates obtaining valuable chemicals, especially oxygen-containing aromatics, from coals. In addition, converting CARs in liquid fuels to water-soluble oxygen-containing aromatics could be a promising approach for effectively removing CARs from liquid fuels.

\section{Acknowledgements}

This work was supported by National Basic Research Program of China (Grant No. 2011CB201302), National Natural Science Foundation of China (Grant No. 21276268), the Fund from Natural Science Foundation of China for Innovative Research Group (Grant No. 51221462), Strategic Chinese-Japanese Joint Research Program (Grant No. 2013DFG60060), the Fundamental Research Fund for the Doctoral Program of Higher Education (Grant No. 20120095110006) and a Project Funded by the Priority Academic Program Development of Jiangsu Higher Education Institutions. 


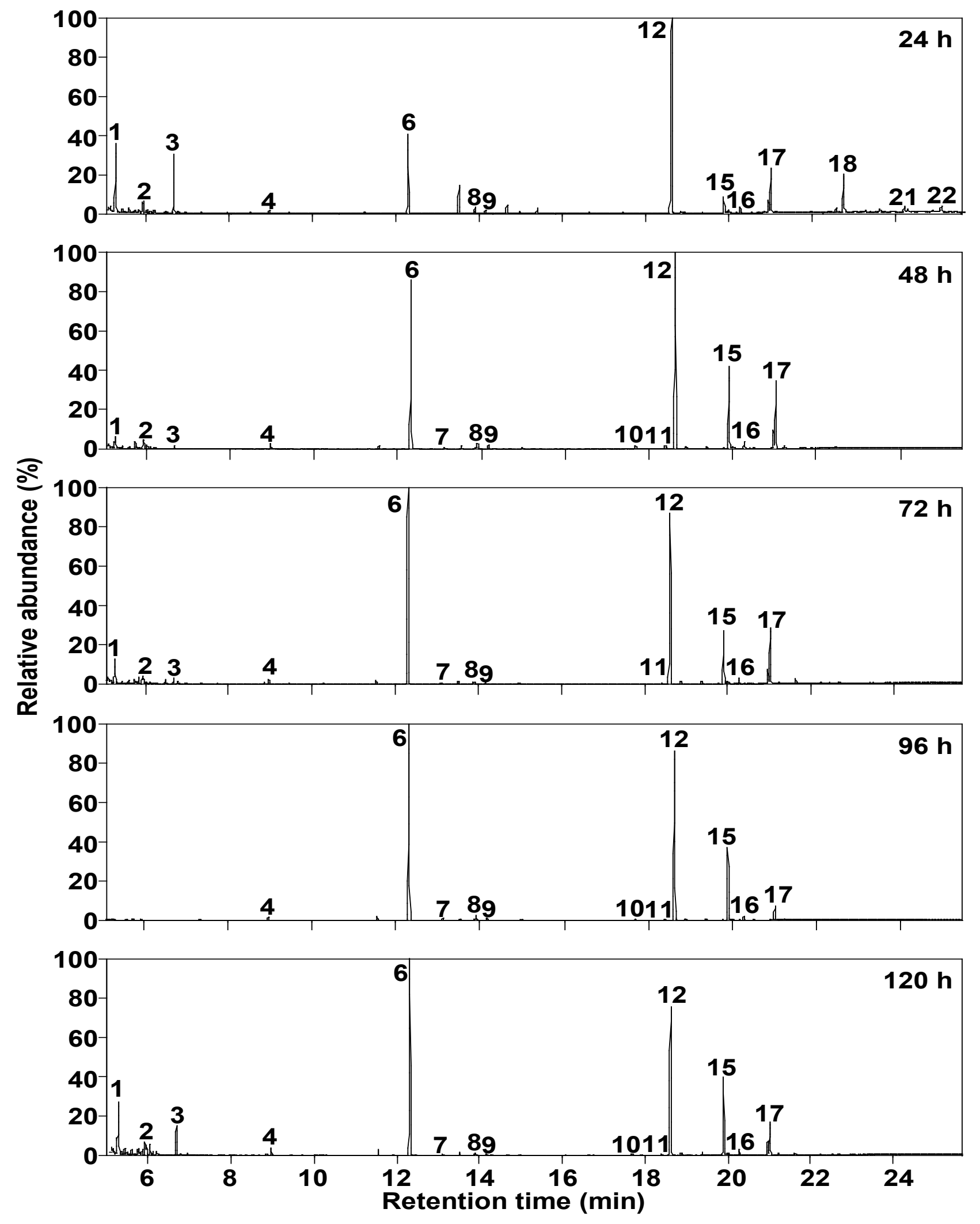

Figure 1 Total ion chromatograms of the methyl esterified products from anthracene oxidation in ASHCS at $30^{\circ} \mathrm{C}$. 


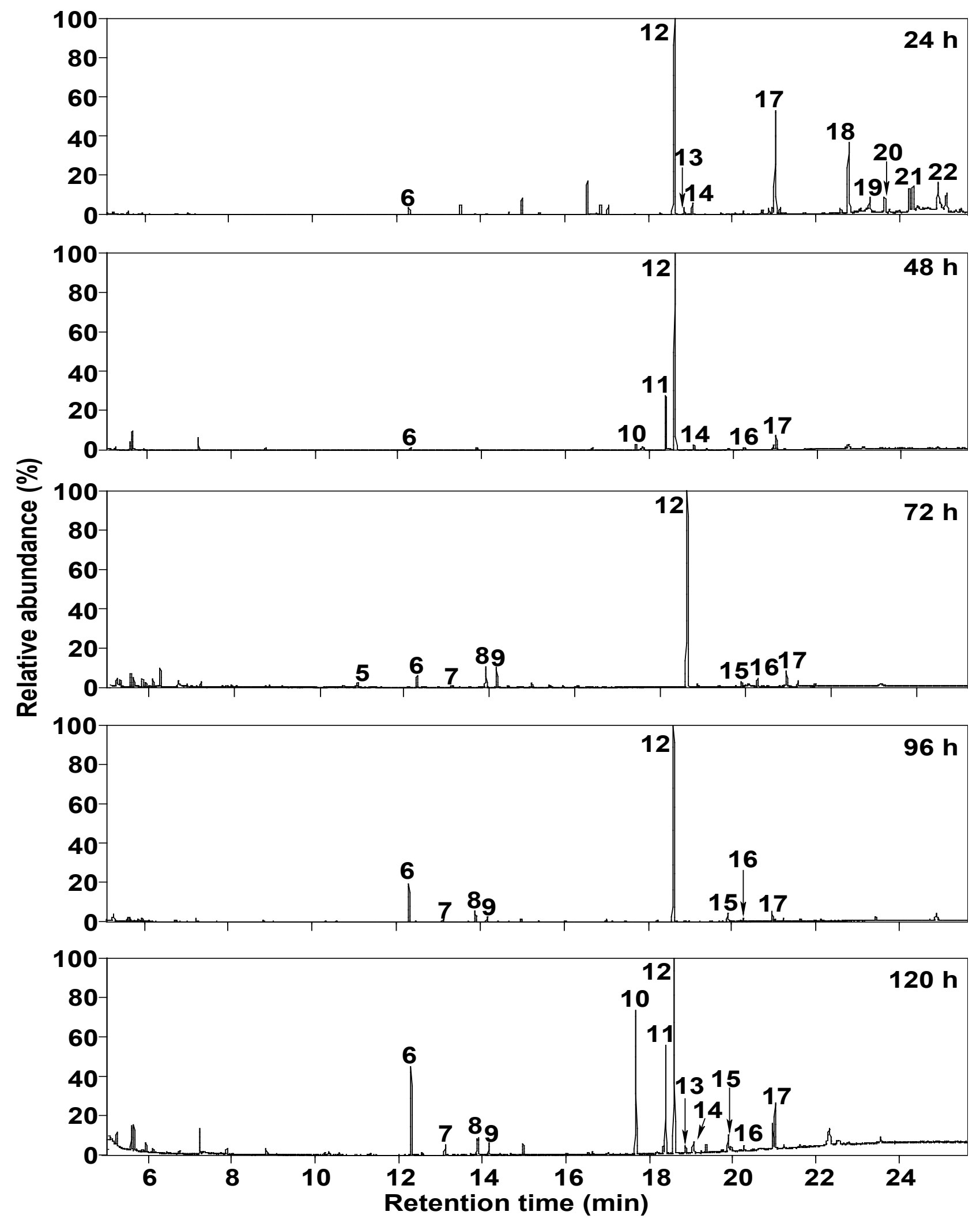

Figure 2 Total ion chromatograms of the methyl esterified products from anthracene oxidation in ASHCS at $40^{\circ} \mathrm{C}$. 


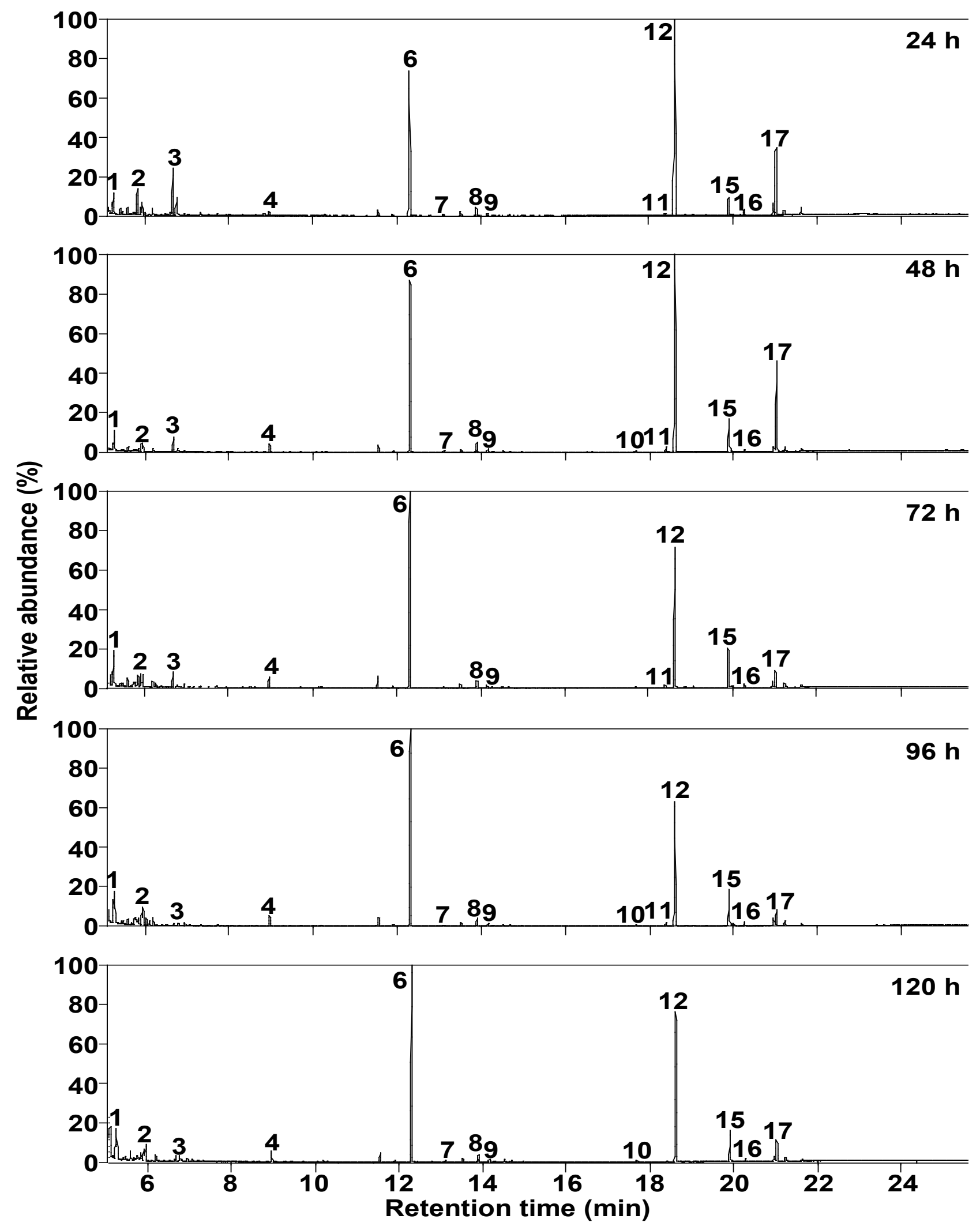

Figure 3 Total ion chromatograms of the methyl esterified products from anthracene oxidation in ASHCS at $50^{\circ} \mathrm{C}$. 
Table 1 Yields ( $\mathrm{mol} \%$ ) of the products from anthracene oxidation in ASHCS at different temperatures.

\begin{tabular}{|c|c|c|c|c|c|c|c|c|c|c|c|c|c|c|c|c|}
\hline \multirow{2}{*}{ Peak } & \multirow{2}{*}{ Parent product } & \multicolumn{5}{|c|}{$30^{\circ} \mathrm{C}$} & \multicolumn{5}{|c|}{$40^{\circ} \mathrm{C}$} & \multicolumn{5}{|c|}{$50^{\circ} \mathrm{C}$} \\
\hline & & $24 h$ & $48 h$ & $72 h$ & $96 h$ & $120 h$ & $24 h$ & $48 h$ & $72 h$ & $96 h$ & $120 h$ & $24 h$ & $48 h$ & $72 h$ & $96 h$ & $120 h$ \\
\hline 1 & 2-Chloroacetic acid & 1.2 & 1.5 & 4.8 & & 9.5 & & & & & & 1.3 & 4.0 & 8.3 & 10.8 & 8.2 \\
\hline 2 & 2,2-Dichloroacetic acid & 0.4 & 1.4 & 2.2 & & 3.4 & & & & & & 1.2 & 1.1 & 2.1 & 2.9 & 2.1 \\
\hline 3 & $\begin{array}{l}\text { 2,2,2-Trichloroacetic } \\
\text { acid }\end{array}$ & 0.9 & 0.3 & 0.9 & & 3.8 & & & & & & 1.9 & 1.9 & 2.5 & 0.3 & 0.8 \\
\hline 4 & Malonic acid & Trace & 0.4 & 0.7 & & 1.0 & & & & & & 0.2 & 1.3 & 2.0 & 1.9 & 2.0 \\
\hline 5 & $\begin{array}{l}\text { Isobenzofuran-1,3- } \\
\text { dione }\end{array}$ & & & & & & & & 1.7 & & & & & & & \\
\hline 6 & Phthalic acid & 1.3 & 17.9 & 34.9 & 39.7 & 33.5 & 0.1 & 0.8 & 3.6 & 12.1 & 12.1 & 6.1 & 29 & 40.1 & 41.6 & 39.0 \\
\hline 7 & $\begin{array}{l}\text { 2-(Ethoxycarbonyl) } \\
\text { benzoic acid }\end{array}$ & & 0.1 & 0.3 & 0.5 & 0.2 & & & 0.4 & 0.9 & 1.4 & 0.1 & 0.3 & & 0.2 & 0.3 \\
\hline 8 & 3-Chlorophthalic acid & 0.1 & 0.7 & 0.3 & 1.3 & 0.5 & & & 6.3 & 5.6 & 5.0 & 0.4 & 1.8 & 1.6 & 1.8 & 1.8 \\
\hline 9 & 4-Chlorophthalic acid & Trace & 0.3 & 0.3 & 0.6 & 0.3 & & & 5.6 & 1.9 & 1.6 & 0.1 & 0.5 & 0.5 & 0.5 & 0.5 \\
\hline 10 & $\begin{array}{l}\text { Biphenyl-2,2'- } \\
\text { dicarboxylic acid }\end{array}$ & & 0.3 & & 0.3 & 0.3 & & 1.8 & & & 19.7 & & 0.2 & & 0.3 & 0.3 \\
\hline 11 & Anthrone & & 0.3 & 0.2 & 0.2 & 0.2 & & 20.6 & & & 17.1 & 0.1 & 0.9 & 0.5 & 0.7 & \\
\hline 12 & Anthraquinone & 4.1 & 24.9 & 34.8 & 40.7 & 28.5 & 5.2 & 69.7 & 74.0 & 74.8 & 29.1 & 11.2 & 37.0 & 31.1 & 28.5 & 34.0 \\
\hline 13 & Chloroanthracene & & & & & & 0.1 & & & & 1.3 & & & & & \\
\hline 14 & Chloroanthracene & & & & & & 0.3 & 1.7 & & & 1.9 & & & & & \\
\hline 15 & Pyromellitic acid & 0.3 & 8.2 & 9.3 & 13.1 & 12.3 & & & 1.3 & 3.1 & 2.7 & 0.8 & 5.5 & 7.3 & 6.7 & 6.1 \\
\hline 16 & Chloroanthraquinone & 0.1 & 0.7 & 1.1 & 0.8 & 1.0 & & 0.7 & 2.4 & 1.2 & 0.9 & 0.3 & 0.4 & 0.7 & 0.6 & 0.6 \\
\hline 17 & Dichloroanthracene & 0.8 & 6.8 & 10.2 & 2.8 & 5.5 & 2.3 & 4.7 & 4.7 & 0.4 & 7.2 & 3.1 & 16.1 & 3.3 & 3.2 & 4.3 \\
\hline 18 & Trichloroanthracene & 0.1 & & & & & 1.9 & & & & & & & & & \\
\hline 19 & Trichloroanthracene & & & & & & 0.5 & & & & & & & & & \\
\hline 20 & Trichloroanthracene & & & & & & 0.4 & & & & & & & & & \\
\hline 21 & Trichloroanthracene & 0.1 & & & & & 0.6 & & & & & & & & & \\
\hline 22 & Tetrachloroanthracene & 0.2 & & & & & 0.8 & & & & & & & & & \\
\hline
\end{tabular}

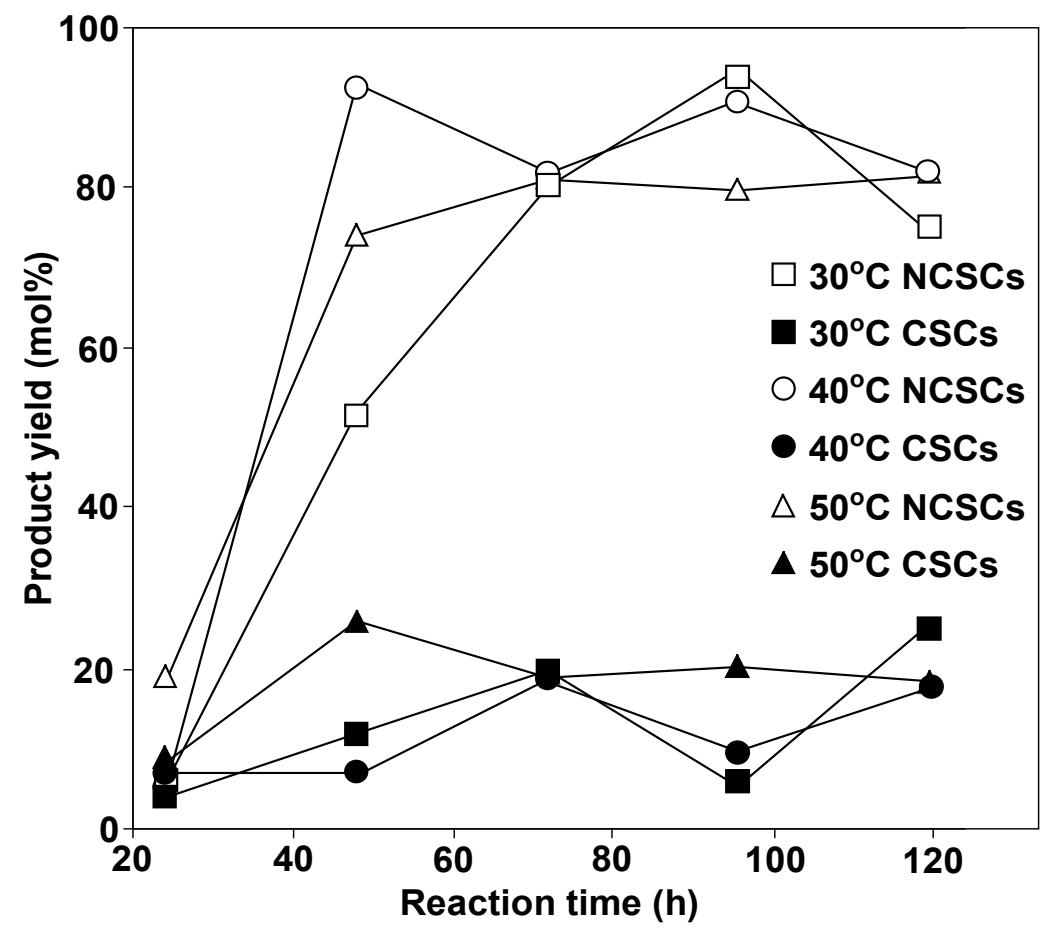

Figure 4 Time profiles of the yields of NCSCS and CSCs from anthracene oxidation in ASHCS at different temperatures. 


$$
\begin{aligned}
\mathrm{NaOCl} & \rightleftharpoons \mathrm{Na}^{+}+{ }^{-} \mathrm{OCl} \\
2^{-} \mathrm{OCl} & \rightleftharpoons \mathrm{O}_{2}^{-\cdot}+\mathrm{Cl}_{2}^{-}
\end{aligned}
$$

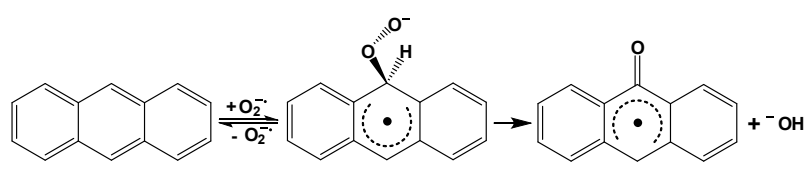<smiles>[TeH4]</smiles><smiles>O=C1c2ccccc2C(=O)c2cc(Nc3ccc4c(c3)C(=O)c3ccccc3[C@H]4O)ccc21</smiles>

$$
\begin{aligned}
\mathrm{Na}^{+}+{ }^{-} \mathrm{OH} & \rightleftharpoons \mathrm{NaOH} \\
\mathrm{Na}^{+}+\mathrm{Cl}_{2}^{-\cdot} & \rightleftharpoons \mathrm{NaCl}+\mathrm{Cl}^{\cdot} \\
2 \mathrm{Cl}^{\cdot} & \rightleftharpoons \mathrm{Cl}_{2}
\end{aligned}
$$

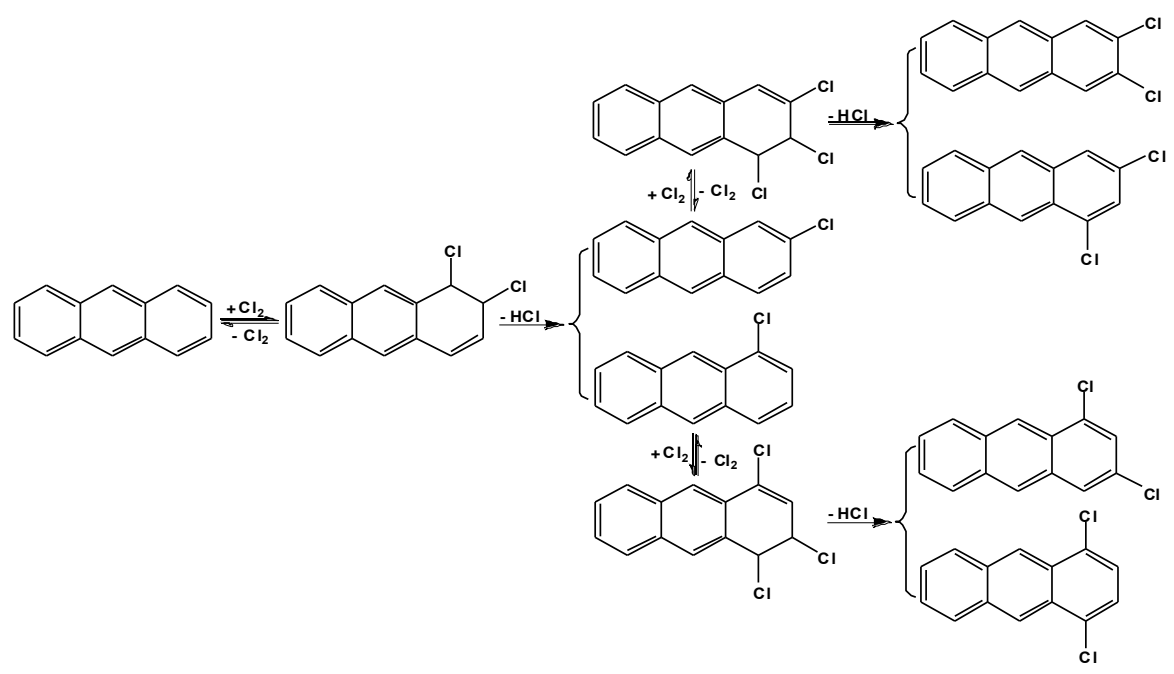

Scheme 1 Possible mechanisms for anthracene oxidation and chlorination in ASHCS.<smiles>O=C(O)C1=CC(Cl)C(Cl)C=C1C(=O)O</smiles>

Scheme 2 Possible mechanisms for PA dehydration and chlorination in ASHCS. 


\section{References}

1 Winans RE, Hayatsu R, Mcbeth RL, Scott RG, Botto RE, et al. (1988) Aromatic structures in whole coals and coal macerals. Prepr Pap Am Chem Soc Div Fuel Chem 33: 407.

2 Miura K, Mae K, Okutsu H, Mizutani NA (1996) New oxidative degradation method for producing fatty acids in high yields and high selectivity from low-rank coals. Energy Fuels 10: 1196-1201.

3 Miura K (2000) Mild conversion of coal for producing valuable chemicals. Fuel Process Technol 62: 119-135.

4 Cooper BH, Donnis BBL (1996) Aromatic saturation of distillates: an overview. Appl Catal A 137: 203-223.

5 Mayo FR (1975) Application of sodium hypochlorite oxidations to the structure of coal. Fuel 54: 273-275.

6 Mayo FR, Kirshen NA (1979) Oxidations of coal by aqueous sodium hypochlorite. Fuel 58: 698-704.

7 Yao ZS, Wei XY, Lv J, Liu FJ, Huang YG, et al. (2010) Oxidation of Shenfu Coal with RuO4 and $\mathrm{NaOCl}$. Energy Fuels 24: 1801-1808.

8 Liu FJ, Wei XY, Zhu Y, Wang YG, Li P, et al. (2013) Oxidation of Shengl lignite with aqueous sodium hypochlorite promoted by pretreatment with aqueous hydrogen peroxide. Fuel 111: 211-215.

9 Wang YG, Wei XY, Yan HL, Liu FJ, Li P, et al. (2014) Sequential oxidation of Jincheng No. 15 anthracite with aqueous sodium hypochlorite. Fuel Process Technol 125: 182-189.

10 Zheng AL, Fan X, Wang SZ, Liu FJ, Wei XY, et al. (2014) Analysis of the products from the oxidation of Geting bituminous coal by atmospheric pressure photoionization-mass spectrometry. Anal Lett 47: 958-969.

11 Chakrabartty SK, Kretschmer HO (1974) Sodium hypochlorite as a selective oxidant for organic compounds. JCS Perkin 1: 222-228.
12 Landolt RG (1975) Oxidation of coal models. Reaction of aromatic compounds with Sodium Hypochlorite. Fuel 54: 299.

13 Angert JL, Gatton SL, Reilly MT, Landolt RG (1977) Role of substituents and $\mathrm{pH}$ in activating hypochlorite oxidations of coal models. Fuel 56: 224-225.

14 Lu Y, Wei XY, Zong ZM, Lu YC, Cao JP, et al. (2013) Organonitrogen compounds identified in degraded wheat straw obtained by oxidation in a sodium hypochlorite aqueous solution. Fuel 109: 61-67.

15 Wang SZ, Fan X, Zheng AL, Lu Y, Wei XY, et al. (2014) Evaluation of the oxidation of rice husks with sodium hypochlorite using gas chromatography-mass spectrometry and direct analysis in real timemass spectrometry. Anal Lett 47: 77-90.

16 Parkin KL, Lowum SE (1990) Active oxygen species involved in the dye- sensitized photoinactivation of mushroom tyrosinase. J Agric Food Chem 38: 1297-1302.

17 Mathy-Hartert M, Deby-Dupont G, Hans P, Deby C, Lamy M, et al. (1998) Protective activity of Propofol, Diprivan ${ }^{\circledR}$ and intralipid against active oxygen species. Mediators Inflamm 7: 327-333.

18 Yamakoshi Y, Umezawa N, Ryu A, Arakane K, Miyata N, et al. (2003) Active oxygen species generated from photoexcited fullerene (C60) as potential medicines: O2-* versus 102. J Am Chem Soc 125: 1280312809.

19 Lev-Goldman V, Mester B, Ben-Aroya N, Koch Y, Weiner L, et al. (2006) Synthesis and active oxygen generation by new emodin derivatives and their gonadotropin-releasing hormone conjugates. Bioconjug Chem 17: 1008-1016.

20 Rivas FJ, García R, García-Araya JF, Gimeno O (2008) Promoted wet air oxidation of polynuclear aromatic hydrocarbons. J Hazard Mater 153: $792-798$

21 Yonezawa T, Nagata C, Koto H, Imamura A, Morakuma K, et al. (1990) Guide to Quantum Chemistry. Kagaku-Dojin Press: Kyoto. p: 232. 